\title{
PROPAGATION OF OVERVOLTAGE WAVES IN ELECTRICAL TRANSFORMERS WITH GUARD RING
}

\author{
PROPAGAREA UNDELOR DE SUPRATENSIUNE ÎN \\ TRANSFORMATOARE PREVĂZUTE CU INEL DE GARDĂ
}

\author{
Alina VIIȘOREANU-RĂCHIȚEANU ${ }^{1}$ şi Alexandru-Marius VIIȘOREANU² \\ ${ }^{1,2}$ Universitatea POLITEHNICA din București, România \\ alina.rachiteanu92@yahoo.com¹, alex.viisoreanu@yahoo.ro²
}

\begin{abstract}
The paper presents a study based on numerical simulation methods of electrical circuits which analyzes the influence of the internal protection elements of the transformer on atmospheric overvoltage. The difference between the time variation curves of the overvoltages propagated along the high voltage range with and without guard ring is shown as the internal protection element of the transformer.
\end{abstract}

Rezumat. În lucrare se prezintă un studiu bazat pe metodele numerice de simulare ale circuitelor electrice prin care se analizează influența elementelor de protecție interioară ale transformatorului la supratensiuni atmosferice. Se arată diferența dintre curbele de variaţie în timp ale suprateniunilor propagate de-a lungul înfăşurării de înaltă tensiune cu și fără inel de gardă, ca element de protecție interioară a transformatorului.

\section{INTRODUCERE}

Undele de supratensiune provocate de trăsnet, care lovesc liniile de transport a energiei electrice, se propagă pe aceste linii şi pot produce avarii importante dacă nu se iau măsuri speciale de protecţie. Aceste supratensiuni ajung mai întâi la înfăşurările de înaltă tensiune ale transformatoarelor electrice de putere aferente acestor linii. Protecţia acestor transformatoare împotriva undelor de trăsnet se realizează prin două categorii de metode: metode exterioare şi metode interioare [1], [2], [3].

Metodele exterioare reduc undele de supratensiune înainte de a ajunge la bornele de intrare ale transformatoarelor electrice şi sunt, în principal, următoarele: descărcătoarele cu rezistenţă variabilă şi eclatoarele.

Descărcătoarele cu rezistenţă variabilă se conectează între linia de transport a energiei electrice şi pământ. Dacă tensiunea liniei este egală cu valoarea nominală a acesteia atunci rezistenţa electrică a descărcătorului este foarte mare şi acesta nu influenţează practic funcţionarea liniei. La apariţia unei supratensiuni de trăsnet rezistenţa descărcătorului scade rapid şi sarcina electrică datorată trasnetului se descarcă în pământ. Descărcătoarele pentru protecţia la supratensiuni a reţelelor electrice de înaltă tensiune se impart în două categorii: descărcătoare cu oxizi metalici fără eclatoare de amorsare și descărcătoare cu carbură de siliciu cu eclatoare de amorsare și rezistoare de șuntare. Diferențele dintre cele două tipuri de descărcătoare sunt doar din punct de vedere constructiv [8].

Eclatoarele se montează între borna de intrare a înfăşurării de înaltă tensiune a transformatorului şi pământ. La apariţia unei supratensiuni de trăsnet de valoare mult mai mare decât tensiunea nominală a liniei electrice apare fenomenul de străpungere a aerului dintre extremităţile eclatorului şi sarcina electrică datorată trăznetului se descarcă în pământ. 
Metodele interioare de protecţie la supratensiuni se realizează practic prin măsuri constructive care se aplică înfăşurării de înaltă tensiune a transformatorului, deoarece aceasta este conectată la linia de transport a energiei electrice. Aceste metode constau în utilizarea câtorva procedee constructive speciale cum ar fi:

- $\quad$ Intărirea izolaţiei de intrare a înfăşurării de înaltă tensiune pentru primele $5 \ldots 10 \%$ ale spirelor acesteia;

- $\quad$ Folosirea unui inel de gardă care reprezintă de fapt o spiră circulară întreruptă;

- Utilizarea unui ecran clindric de protecţie secţionat după generatoare pentru a nu forma o spiră în scurtcircuit;

- $\quad$ Intercalarea sau întreţeserea spirelor înfăşurării folosită la înfăşurările în galeţi.

Întărirea izolaţiei spirelor de intrare ale înfăşurării de înaltă tensiune conduce la creşterea grosimii izolaţiei acestor spire şi la mărirea distanţei dintre spire cu consecinţe asupra scăderii capacităţii dintre acestea. Din acestă cauză, se preferă ca pentru spirele de intrare să se folosească o izolaţie cu caracteristici dielectrice superioare, pentru a rămâne pe cât posibil capacitatea dintre spire neschimbată, pe toată lungimea înfăşurării de înaltă tensiune. Unele firme constructoare utilizează, pentru spirele de intrare ale înfăşurării, conductoare de înălţime mai mare, care conduce la mărirea capacităţii dintre spire.

Modificarea capacităţii dintre spirele de intrare ale înfăşurării de înaltă tensiune, respectiv modificarea dintre aceste spire şi masă se poate face prin folosirea unui inel de gardă care se conectează la borna de intrare a înfăşurării de înaltă tensiune. Acesta se realizează prin bandajarea cu o bandă realizată dintr-o ţesătură metalică, a unui inel realizat dintr-un material izolant. Țesătura metalică cu care se bandajează inelul este întreruptă pentru a nu forma o spiră în scurtcircuit. Tesătura metalică se foloseşte pentru evitarea producerii unor pierderi suplimentare provocate de câmpul magnetic de dispersie la funcţionarea în sarcină a transformatorului, cu consecinţe nedorite din punct de vedere termic.

La transformatoarele cu înfăşurări cilindrice stratificate se pot utiliza ecrane cilindrice metalizate, dispuse la exteriorul înfăşurării de înaltă tensiune şi conectate la borna de intrare a înfăşurării. Ecranul este secţionat după generatoare pentru a nu forma o spiră în scurtcircuit.

De asemenea, ecranul cilindric prezintă foarte multe tăieturi, paralele cu generatoarea, pentru a nu produce pierderi suplimentare mari de către curenţii induşi de câmpul magnetic de dispersie la funcţionarea în sarcină a transformatorului.

Intercalarea spirelor înfăşurării de înaltă tensiune se poate realiza pentru înfăşurările realizate în galeţi, numai în cazul în care spira este formată din două sau mai multe conductoare elementare conectate în paralel. Prin această intercalare conductoarele elementare ale unei spire care se succed în circuitul electric al acesteia nu mai sunt aşezate alăturat ci sunt intercalate. În literatura tehnică, procedeul de intercalare pentru conductoarele elementare ale spirei se mai numeşte şi transpoziţia conductoarelor elementare ale acesteia. Această transpoziţie se realizează pe toată lungimea înfăşurării de înaltă tensiune.

\section{ELEMENTELE DE PROTECŢIE INTERIOARĂ TRANSFORMATORULUI LA SUPRATENSIUNI ATMOSFERICE}

ALE

Cele mai importante elemente de protecție interioară enumerate în paragraful anterior sunt folosirea unui inel de gardă şi utilizarea unui ecran clindric de protecţie secţionat după generatoare.

În Fig. 1 se prezintă schematic un transformator monofazat, prevăzut cu inel de gardă și cu ecran de protecție. Se constată că la borna de intrare A, a înfăşurării de înaltă tensiune AX se conectează atât inelul de gardă cât şi ecranul de protecţie. 


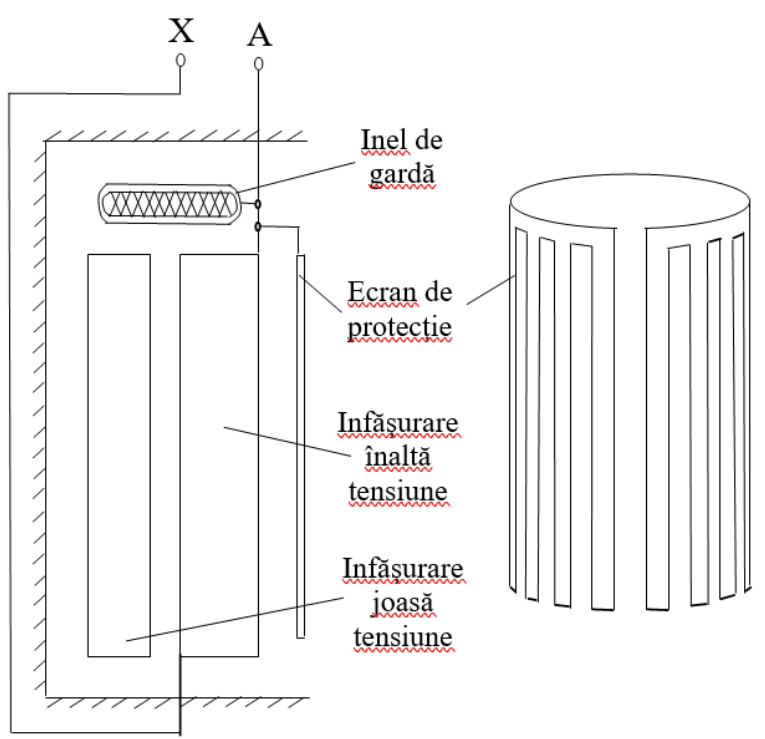

Fig. 1. Înfăşurările şi elementele de protecţie interioară, la supratensiuni atmosferice, ale transformatorului

Cele două elemente de protecție interioară prezintă avantajul că diminuează șocul inițial datorat frontului undei de supratensiune atmosferică în sensul că unda de supratensiune se repartizează mai uniform de-a lungul înfășurării de înaltă tensiune și ajută la protecția dielectrică a spirelor de intrare ale acestei înfășurări.

\section{INFLUENȚA INELULUI DE GARDĂ ASUPRA REPARTIȚIEI SUPRATENSIUNII DE-A LUNGUL ÎNFĀȘURĂRII}

Pentru început, se consideră cazul din lucrarea [4] și [6] în care se prezintă schema echivalentă a transformatorului la supratensiuni, în lipsa atât a ecranului de protecție cât și a inelului de gardă. Această schemă echivalentă este prezentată în Fig. 2 și este formată din 6 secțiuni identice din punct de vedere al parametrilor acestor secțiuni. Valorile celor 5 parametrii care apar în acestă schemă sunt următoarele [4]: $R_{\mathrm{oL}}=2 \Omega, R_{\mathrm{OT}}=2000 \mathrm{M} \Omega$, $L_{\mathrm{oL}}=2 \mathrm{mH}, C_{\mathrm{oL}}=2.2 \mathrm{nF}, C_{\mathrm{oT}}=5.5 \mathrm{nF}$. Aceste valori sunt denumite în continuare ,valori de referință”.

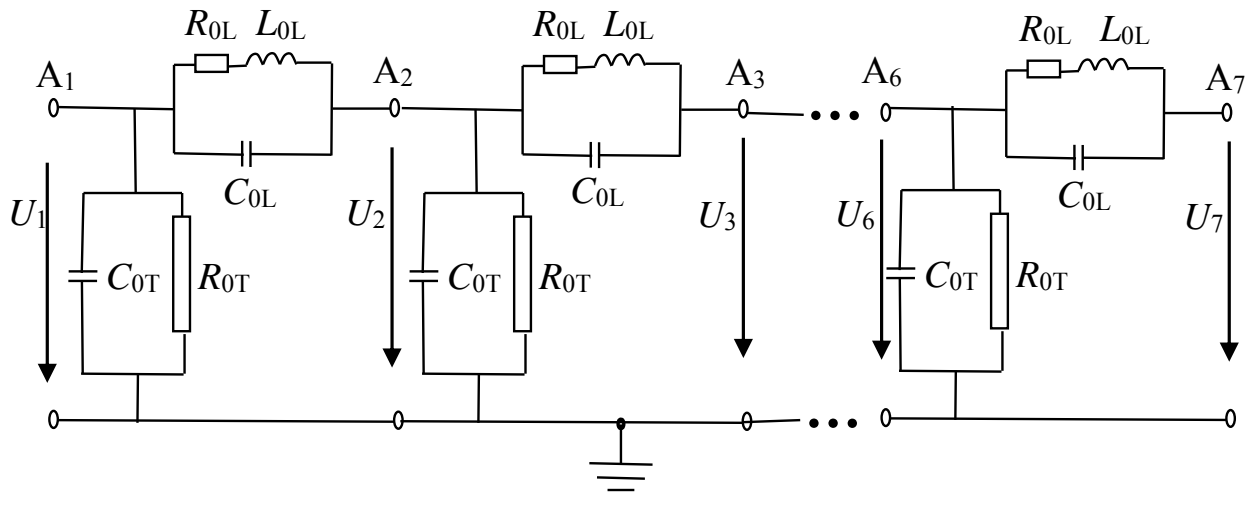

Fig. 2. Schema echivalentă a transformatorului la supratensiuni considerând valori identice ale celor 6 secțiuni ale înfăşurării de înaltă tensiune 
Se aplică la borna de intrare a transformatorului un impuls dreptunghiular de tensiune standard, a cărei valoare de vârf este de $U=1 \mathrm{kV}$. Se modelează în LT Spice propagarea în timp şi spaţiu a undei de supratensiune, pentru valorile de referinţă, de mai sus, ale parametrilor schemei echivalente şi se obţin curbele din Fig. 3.

Este evident, că modelarea în timp a undelor de tensiune sunt funcţii continue, dar modelarea în spaţiu o reprezintă cele 6 funcţii discrete, reprezentând tensiunile determinate la cele şase borne de intrare $A_{1}, A_{2}, \ldots, A_{6}$, ale celor şase circuite discrete în care s-a împărţit înfăşurarea de înaltă tensiune a transformatorului.

Curbele prezentate în Fig. 3 reprezintă variația în timp a undelor de supratensiune calculate pentru bornele de intrare $\mathrm{A}_{1}, \mathrm{~A}_{2}, \ldots, \mathrm{A}_{6}$, în cazul în care nu se consideră nici prezenţa inelului de gardă și nici prezența ecranului de protecție.

Determinarea capacității ecranului de protecție și influența acestuia asupra repartiției undei de supratensiune de-a lungul înfăşurării de înaltă tensiune este realizată în lucrarea [5] și nu face obiectul prezentei lucrari.

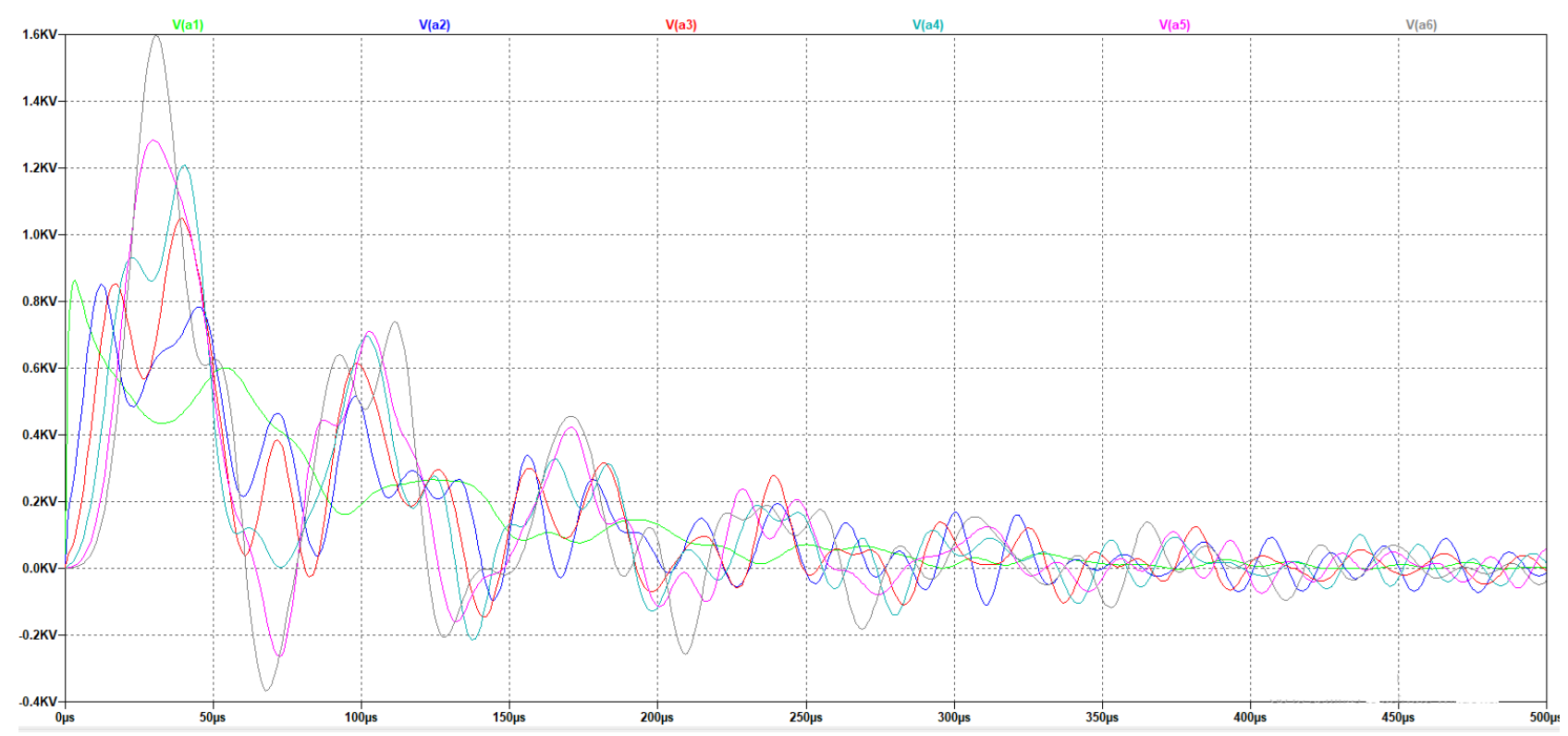

Fig. 3. Curbele de variaţie în timp ale suprateniunilor propagate de-a lungul înfăşurării de înaltă tensiune, simulate pentru bornele de intrare ale celor 6 secţiuni, considerand schema electrică prezentată în Fig. 2. Legenda culorilor curbelor este următoarea: borna A1 - culoarea verde; borna A2 - culoarea albastru închis; borna A3 - culoarea roşie; borna A4 - culoarea albastru deschis (bleu); borna A5 - culoarea magenta; borna A6 - culoarea neagră.

În prezenta lucrare se analizează situația în care transformatorul este prevăzut doar cu inel de gardă, iar ecranul de protecție lipsește. În acest caz, se studiază influența inelului de gardă asupra schemei echivalente a transformatorului. Asa cum se prezintă în lucrarea [7], atât ecranul de protecție cât și inelul de gardă sunt introduse în schema echivalentă la supratensiuni ale transformatorului prin capacități suplimentare conectate între înfășurărea de înaltă tensiune și masă. Inelul de gardă se conectează electric la borna de intrare a înfăşurării de înaltă tensiune. Pentru a lua în seamă prezența inelului de gardă asupra schemei echivalente se consideră că acesta introduce în schema echivalentă la supratensiuni, 6 capacități corespunzătoare celor 6 secțiuni ale înfășurării de înaltă tensiune. Se face ipoteza ca valorile acestor capacități sunt diferite pentru cele 6 secțiuni ale înfășurării de înaltă tensiune, 
cea mai mare valoare fiind asociată secțiunii de la intrarea înfășurării și cea mai mică valoare fiind asociată ultimei secțiuni de la finalul înfășurării de înaltă tensiune.

În Fig. 4 se prezintă schema echivalentă a transformatorului considerând că acesta este prevăzut doar cu inel de gardă nu și cu ecran de protecție.

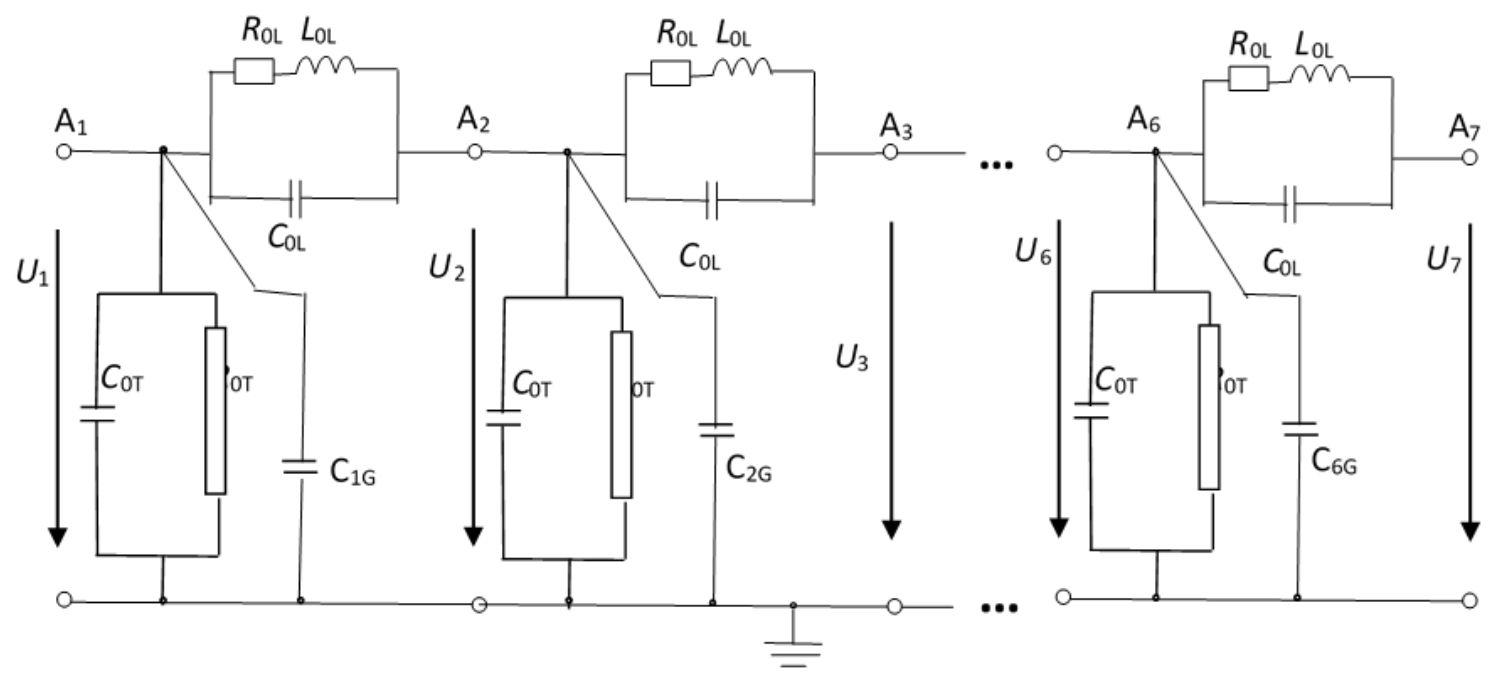

Fig. 4. Schema echivalentă a transformatorului la supratensiuni considerând și existența inelului de gardă

După cum se observă, inelul de gardă introduce în schema echivalentă a transformatorului capacitățile $\mathrm{C}_{1 \mathrm{G}}, \mathrm{C}_{2 \mathrm{G}}, \ldots, \mathrm{C}_{6 \mathrm{G}}$, capacități care formează un șir descrescător, cea mai mare valoare fiind asociată primei secțiuni de intrare $A_{1}$ a transformatorului. Se face ipoteza ca cele 6 capacități, caracteristice inelului de gardă, corespunzătoare schemei echivalente din Fig. 4 au valorile prezentate în Tab. 1.

Tab. 1. Valorile capacităţilor $\mathrm{C}_{1 \mathrm{G}}, \mathrm{C}_{2 \mathrm{G}}, \ldots, \mathrm{C}_{6 \mathrm{G}}$

\begin{tabular}{|l|l|ll|}
\hline $\mathrm{C}_{1 \mathrm{G}}$ & $10 \mathrm{nf}$ & 10 & $\mathrm{nF}$ \\
\hline $\mathrm{C}_{2 \mathrm{G}}$ & $\mathrm{C}_{1 \mathrm{G}} / 2$ & 5 & $\mathrm{nF}$ \\
\hline $\mathrm{C}_{3 \mathrm{G}}$ & $\mathrm{C}_{1 \mathrm{G}} / 3$ & 3.3333 & $\mathrm{nF}$ \\
\hline $\mathrm{C}_{4 \mathrm{G}}$ & $\mathrm{C}_{1 \mathrm{G}} / 4$ & 2.5 & $\mathrm{nF}$ \\
\hline $\mathrm{C}_{5 \mathrm{G}}$ & $\mathrm{C}_{1 \mathrm{G}} / 5$ & 2 & $\mathrm{nF}$ \\
\hline $\mathrm{C}_{6 \mathrm{G}}$ & $\mathrm{C}_{1 \mathrm{G}} / 6$ & 1.6666 & $\mathrm{nF}$ \\
\hline
\end{tabular}

Această ipoteză presupune că valorile capacităților corespunzătoare inelului de gardă au o descreștere liniară pentru cele 6 secțiuni ale înfășurării de înaltă tensiune.

În mod asemănător cu simulările efectuate în cazul schemei din Fig. 2 se reiau simulările în programul de calcul LT Spice și se modelează propagarea în timp și în spatiu a aceleași undă de spratensiune de valoare $1 \mathrm{kV}$, aplicată bornei de intrare a înfășurării de înaltă tensiune, unda care s-a folosit și pentru determinarea caracteristicilor prezentate în Fig. 3. În acestă nouă situație se obțin curbele prezentate în Fig. 5. 


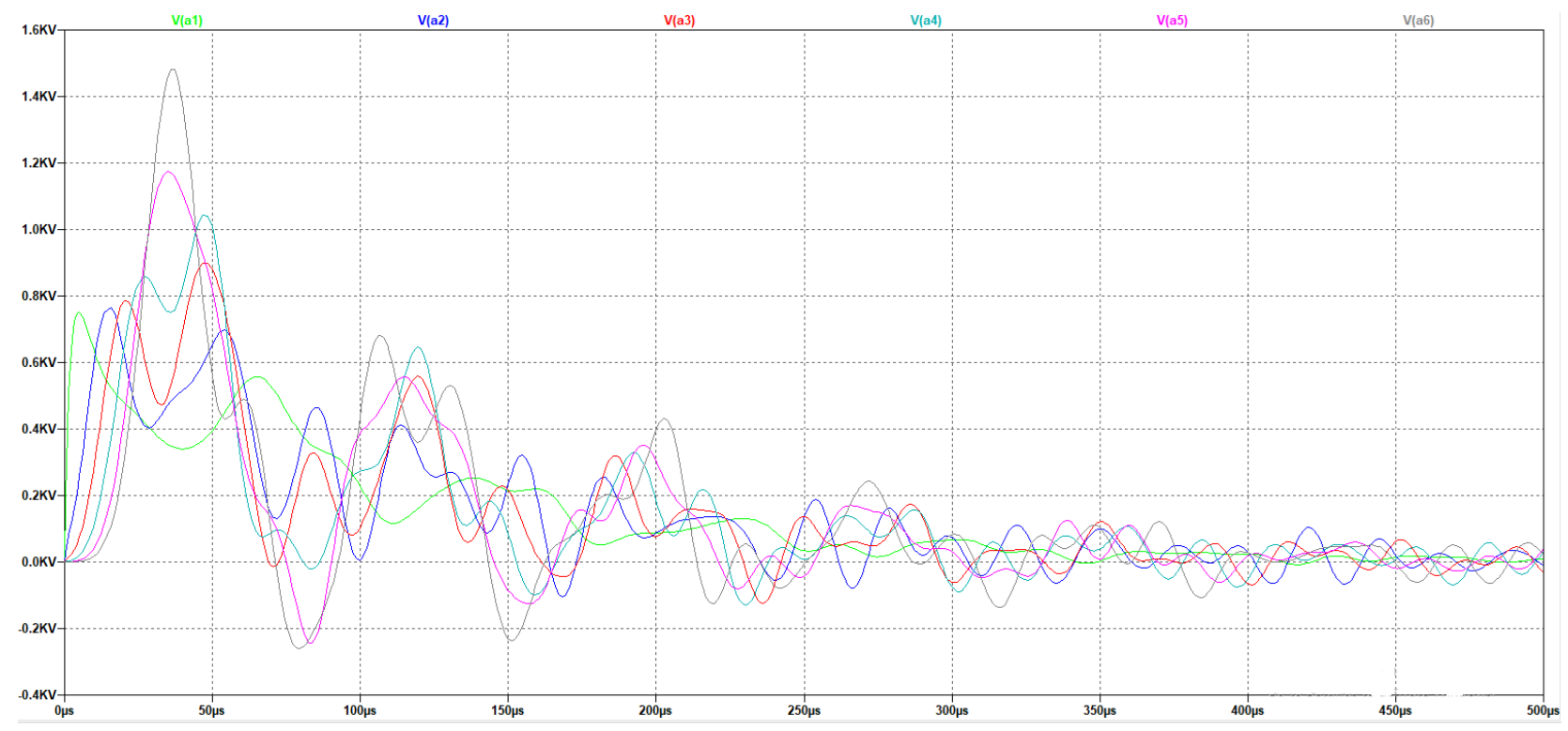

Fig. 5. Curbele de variaţie în timp ale suprateniunilor propagate de-a lungul înfăşurării de înaltă tensiune, simulate pentru bornele de intrare ale celor 6 secţiuni, considerand schema electrică prezentată în Fig. 4. Legenda culorilor curbelor este următoarea: borna A1 - culoarea verde; borna A2 - culoarea albastru închis; borna A3 - culoarea roşie; borna A4 - culoarea albastru deschis (bleu); borna A5 - culoarea magenta; borna A6 - culoarea neagră.

Dacă se compară curbele din Fig. 3 cu acelea din Fig. 5 se pot trage două concluzii mai importante cu privire la influența inelului de gardă asupra repartiției undei de supratensiune care se propagă de-a lungul înfășurării de înaltă tensiune. Acestea sunt urmatoarele:

a. Inelul de gardă conduce la diminuarea maximelor tuturor undelor de supratensiune corespunzătoare celor 6 sectiuni ale înfăsurării de înaltă tensiune, cu valori cuprinse între $(7,15 \ldots 14,30) \%$. Astfel, reducerile celor mai mari maxime din cele 6 secțiuni ale înfășurării de înaltă tensiune, datorate prezenței inelului de gardă, sunt prezentate în Tab. 2.

Tab. 2. Valorile procentelor de reducere a maximelor datorate prezenței inelului de gardă

\begin{tabular}{|c|c|c|}
\hline $\begin{array}{c}\text { Secțiunea înfăsurării } \\
\text { de înaltă tensiune }\end{array}$ & $\begin{array}{c}\text { Maximul undei de } \\
\text { supratensiune a secțiunii } \\
\text { fără considerarea inelului } \\
\text { de gardă }\end{array}$ & $\begin{array}{c}\text { Procentul de reducere a } \\
\text { maximului datorat } \\
\text { inelului de gardă }\end{array}$ \\
\hline $\mathrm{A}_{1}$ & $0,86 \mathrm{kV}$ & $13,09 \%$ \\
\hline $\mathrm{A}_{2}$ & $0,85 \mathrm{kV}$ & $10,09 \%$ \\
\hline $\mathrm{A}_{3}$ & $1,04 \mathrm{kV}$ & $14,30 \%$ \\
\hline $\mathrm{A}_{4}$ & $1,20 \mathrm{kV}$ & $13,82 \%$ \\
\hline $\mathrm{A}_{5}$ & $1,28 \mathrm{kV}$ & $8,58 \%$ \\
\hline $\mathrm{A}_{6}$ & $1,59 \mathrm{kV}$ & $7,15 \%$ \\
\hline
\end{tabular}

b. Introducerea inelului de gardă are o influență și asupra vitezei de propagare a undei de supratensiune de-a lungul înfăsurării de înaltă tensiune. Astfel, prezența inelului de gardă conduce la scăderea vitezei de propagare a supratensiunii cu aproximativ $7 \%$. 


\section{CONCLUZII}

Inelul de gardă folosit ca mijloc de protecție la supratensiuni a transformatoarelor electrice este important deoarece conduce la reducerea maximelor undelor de supratensiune care se propagă de-a lungul înfășurării de înaltă tensiune ale acestor transformatoare.

Pe de altă parte, inelul de gardă mai are influență asupra vitezei de propagare a undei de supratensiune în sensul scăderii acesteia cu aproximativ 7 procente. Existența inelului de gardă are influență asupra schemei echivalente la supratensiuni a transformatorului deoarece prezența acestui inel introduce în schema echivalentă capacităti aferente tuturor celor 6 secțiuni ale înfășurării de înaltă tensiune [7].

Studiul realizat în prezenta lucrare nu consideră și existența unui ecran de protecție la supratensiuni pentru transformatorul studiat.

\section{BIBLIOGRAFIE}

[1] C. Bălă, Maşini electrice (Electric Machines), Editura Didactică şi Pedagogică, Bucureşti, 1979.

[2] D. Gleb, Tehnica tensiunilor înalte (High Voltage Techniques), vol. 2, Editura Academiei Române şi Editura AGIR, Bucureşti, 2001.

[3] Heller, B., Veverka, A. Stossercheinungen in elektrischen Maschinen, Berlin, VEB Verlag Technik, 1957.

[4] Ioan - Dragoş Deaconu, Aurel - Ionuţ Chirilă, Valentin Năvrăpescu, Alina Răchiţeanu, Alexandru Marius Viişoreanu, Constantin Ghiţă, Cristina - Gabriela Sărăcin, Lightning Impulse Voltage Modeling for Transformer Windings Testing, The 11-th International Symposium on Advenced Topics in Electrical Engineering, March 28 - 30 2019, Bucharest Romania;

[5] Ioan - Dragos DEACONU, Aurel - Ionut CHIRILA, Constantin GHITA, Valentin NAVRAPESCU, Alina RACHITEANU, Alexandru - Marius VIISOREANU, Sergiu Valentin POPESCU, Corina - Ioana GHEORGHIU, Cristina - Gabriela SARACIN, Determination of the Electric Capacitance of the Overvoltage Protective Shield of an Electric Transformer, The 12-th International Symposium on Advenced Topics in Electrical Engineering, March 25 - 27, 2021, Bucharest, Romania.

[6] Aurel-Ionuț CHIRILĂ, Ioan-Dragoș DEACONU, Valentin NĂVRĂPESCU, Constantin GHIȚĂ, Alina RĂCHIȚEANU, Alexandru-Marius VIIȘOREANU, The Influence of Parameters of a Power Transformer Winding Equivalent Distributed Circuit Model on Atmospheric Overvoltage Wave Internal Propagation along the Windings, The $11^{\text {th }}$ International Conference and Exposition on Electrical and Power Engineering - EPE 2020, October 22 - 23, Iaşi, Romania.

[7] M. Kostenko, L. Piotrovski, Machines Electriques, Edition Mir, Moscou, 1969, Tome I, Machines a courant continuu et transformateurs, pag. $536-540$.

[8] Alina VIIȘOREANU-RĂCHIȚEANU, Alexandru-Marius VIIŞOREANU, Overvoltage protection of transformers and high voltage networks by surge arrester, Revista Energie, Mediu, Eficienta, Resurse, Globalizare - EMERG, Nr. 2. 2020, Pag. 87 - 97; DOI: 10.37410/EMERG. 